\title{
Crop-noncrop spillover: arable fields affect trophic interactions on wild plants in surrounding habitats
}

\author{
David J. Gladbach • Andrea Holzschuh • \\ Christoph Scherber · Carsten Thies • \\ Carsten F. Dormann · Teja Tscharntke
}

Received: 4 May 2010/Accepted: 23 November 2010/Published online: 14 December 2010

(c) The Author(s) 2010. This article is published with open access at Springerlink.com

\begin{abstract}
Ecosystem processes in agricultural landscapes are often triggered by resource availability in crop and noncrop habitats. We investigated how oilseed rape (OSR; Brassica napus, Brassicaceae) affects noncrop plants in managed systems and semi-natural habitat, using trophic interactions among wild mustard (Sinapis arvensis, Brassicaceae), rape pollen beetles (Meligethes aeneus, Nitidulidae) and their parasitoids (Tersilochus heterocerus, Ichneumonidae). We exposed wild mustard as phytometer plants in two cropland habitat types (wheat field, field margin) and three noncrop habitat types (fallow, grassland, wood margin) across eight landscapes along a gradient from simple to complex (quantified as $\%$ arable land). Both landscape and local factors affected the abundance of rape pollen beetles and parasitoids. Rape pollen beetle infestation and parasitism rates on these plants were lower in
\end{abstract}

Communicated by Jay Rosenheim.

Electronic supplementary material The online version of this article (doi:10.1007/s00442-010-1870-3) contains supplementary material, which is available to authorized users.

D. J. Gladbach $(\bowtie) \cdot$ A. Holzschuh · C. Scherber · C. Thies ·

T. Tscharntke

Agroecology, Department of Crop Science, Georg-August

University Göttingen, Griesebachstraße 6, 37077 Göttingen, Germany

e-mail: david.gladbach@web.de

A. Holzschuh

Department of Animal Ecology I, Population Ecology,

University of Bayreuth, Universitätsstr. 30,

95447 Bayreuth, Germany

\section{F. Dormann}

Department of Computational Landscape Ecology, Helmholtz Centre for Environmental Research, UFZ, Permoserstr.15, 04318 Leipzig, Germany noncrop habitats and higher in wheat fields and field margins, whereas beetles and parasitoids responded differently to landscape scale parameters. We found the hypothesized spillover from OSR crop onto wild plants in surrounding habitats only for parasitoids, but not for pollen beetles. Parasitism rates were not related to landscape simplification, but benefited from increasing proportions of OSR. In contrast, rape pollen beetles benefited from simple landscape structures, presumably due to multi-annual population build-ups resulting from long-term OSR planting (as part of the crop rotation). In conclusion, we showed that spillover from cropland affects parasitism rates on related wild plants outside cropland, which has not been shown so far, but can be expected to be a widespread effect shaping noncrop food webs.

Keywords Habitat identity · Herbivory - Large-scale effects · Local effects

\section{Introduction}

Landscape-scale patterns (sensu Turner and Gardner 1991) often affect ecosystem processes locally (Kareiva and Wennergren 1995; Hooper et al. 2005). Spatial configuration and composition of ecosystems and habitat diversity (Turner 1989) have been shown to be interwoven with land-use intensity (e.g., Wrbka et al. 2004), and may influence, as landscape effects, important trophic interactions such as biocontrol and herbivory (Gardiner et al. 2009) or pollination (Ricketts et al. 2008). Hence, both ecosystem services and dis-services (Zhang et al. 2007) in different agro-environments are promoted or constrained to various extents depending on landscape effects. Further, local effects such as habitat type and quality (habitat 
identity) influence diversity and population size of organisms (Matter and Roland 2002; Haynes et al. 2007; Zaller et al. 2008a). Thus, local interactions are triggered by factors such as resource availability at both the landscape and the local habitat scale. However, most studies focus either on just local effects or the distribution of only one habitat type within a landscape (Meyer et al. 2009). Only a few studies have shown the interaction of landscape and local processes and their effect on patterns of insect diversity or trophic interactions (Cushman and McGarigal 2004; Dauber et al. 2005; Schweiger et al. 2005). As a simultaneous investigation of local and landscape patterns is difficult, an experimental approach introducing the same study system in a wide range of habitats and landscapes is a suitable, but little explored technique.

Here, we study the rape pollen beetle Meligethes aeneus (Fabricius 1775), which is one of the most important pest organisms in oilseed rape (OSR; Brassica napus, L.) (Büchi 2002; Alford et al. 2005). Published studies focused on pollen beetles and their parasitoids on OSR and emphasized that landscape context influences trophic interactions in cropland (e.g., Thies and Tscharntke 1999; Ricketts et al. 2008; Büchi 2002; Bianchi et al. 2006; Thies et al. 2008), whereas wild Brassicaceae have been considered only in their potential role as alternative host plants and not as a substitute resource when OSR fields are not longer available. Thus, examples of crop-noncrop spillover are almost absent (Rand et al. 2006). However, spillover may shape trophic interactions and thus we focus on the effect of cropland such as OSR on wild plants in noncrop habitats as well as in crop systems. Although existing theories predict the spillover of insects from crop to noncrop areas (Tscharntke et al. 2005; Rand et al. 2006; Rand and Louda 2006), we are not aware of studies that actually test how the huge and functionally important crop-related populations distribute across different habitats in the landscape shaping food webs,

In the present study, we investigated how landscape composition affects crop-noncrop spillover and associated trophic interactions. We quantified flower herbivory by rape pollen beetles and its parasitism by an ichneumonid wasp (Nilsson 2003) in different habitat types across a gradient of landscape complexity. Spillover may vary due to the source capacity as well as the attractiveness of the destination.

We hypothesize: (1) that both habitat type and landscape characteristics influence the spillover of pollen beetles (M. aeneus) and and parasitism by Tersilochus heterocerus (Thomson 1889) across the crop-noncrop interface; and (2) that increasing proportions of OSR as source habitat increases populations of specialized parasitoids more than their generalist hosts (following Thies et al. 2008), thereby affecting parasitism rates.

\section{Methods}

\section{Experimental setup}

The study was conducted after the flowering period of OSR from 1 June to 15 July 2006 in the vicinity of Göttingen, Lower Saxony, Germany $\left(51^{\circ} 32^{\prime} \mathrm{N}, 9^{\circ} 56^{\prime} \mathrm{E}\right)$. The regional landscape pattern varies from intensively managed, simply structured landscapes that undergo a large inter-annual change (arable land up to 90\%) to complex, extensively managed landscapes with a high proportion of near-natural, perennial habitats, (i.e., fallow, wood margin; arable land $<20 \%$ ). Eight landscapes, (i.e., landscape sectors) were chosen along this gradient of land-use intensity (Online Resource 1). There was no spatial correlation in the landuse gradient of the landscapes. Within each of the landscapes, we established study plots in five major habitat types (cereal field, field margin, fallow, grassland, wood margin) yielding a total of 40 plots. Field margins were chosen adjacent to cereal fields, wood margins were adjacent to cereal field, maize, or grassland. The locations of the habitats within landscapes were chosen as near to each other as possible (mean $123 \pm \mathrm{SE} 12 \mathrm{~m}$ ), in order to achieve maximum similarity with respect to landscapescale parameters. Distance of habitats to the nearest OSR crops (mean $197 \pm$ SE $22 \mathrm{~m}$ ) was tested in linear mixed effects models (lme models; Pinheiro et al. 2009) in R 2.9.11 (R Development Core Team 2009) and did not vary significantly $\left(F_{4,21}=1.81, p=0.147\right)$. In each habitat we established (1 June) a plot of three wild mustard plants (S. arvensis), which are native rural plants found ubiquitously in agricultural and semi-natural habitats flowering from April to October. These sample plants served as phytometers and were grown in pots under standardized conditions in the same soil (standard garden soil, watered every second day), before the start of the experiment. With this phytometer approach, we achieved a maximum of similarity between our sampling units in the different habitats and landscapes. Excluding differences in plant quality was particularly important for this study, because it can change the oviposition rate of rape pollen beetles (Hopkins and Ekbom 1996). As part of the family Brassicaceae, wild mustard is greatly preferred to other yellow flowering plant families by $M$. aeneus (see above). Avoiding competition of the phytometers with other plants within the habitats was important in order to obtain a reliable measure of overspilling target organisms. This competition was minimized by choosing only habitats with low cover of alternative brassicacea plants (highest cover of non phytometer brassicacea was $2 \%$ B. napus in one plot; Online resource 2). From the time when rape pollen beetles dispersed from the fading OSR fields, the phytometers were freely accessible for rape pollen beetles and 
their parasitoids, so that differences due to local and landscape effects would be recognizable through population density and parasitism rates.

\section{Study species}

All developmental stages of rape pollen beetle $M$. aeneus (Coleoptera: Nitidulidae) feed on pollen. M. aeneus is one of the economically most important pest species on OSR, preventing seed development and hence causing loss of yield, but the species also feeds on a range of other plant species (Charpentier 1985), such as wild mustard, our phytometer (Ekbom and Borg 1996; Cook et al. 2006). In late April, adults start moving into (not yet flowering) OSR crops for maturity feeding and subsequent oviposition. In field conditions, the reproductive period usually lasts 2 months, but rape pollen beetles have been shown to exhibit reproductive plasticity depending on environmental or host plant conditions (Ekbom and Borg 1996; Billqvist and Ekbom 2001). In ideal conditions, oviposition may take place until October, and observations of beetles laying eggs in the year of their hatching have also been observed (Bromand 1983). Larvae of rape pollen beetles develop in flowers, drop to the ground on maturity, pupate and emerge after 1-5 weeks. Beetles live on a variety of plants (Hokkanen 2000; Gurr et al. 2003; Lehrman et al. 2008) when OSR crops have faded. Adults of the first generation die after egg laying, second generation beetles move into hibernating sites under herbaceous vegetation or moist woodland debris (Müller 1941; Nilsson 1988; Williams 2004). The larvae of the rape pollen beetle are attacked by the univoltine parasitoids, T. heterocerus, Phradis interstitialis, and Phradis morionellus (Hymenoptera: Ichneumonidae), of which the last is rare. The parasitoids are specialized on rape pollen beetles and attack host larvae in the first (Phradis spp.) and second (T. heterocerus) instar. After parasitizing the larvae in the flower, both endo-parasitoid species kill their host larvae after they drop to the ground before pupation in the soil (Jourdheuil 1960). Parasitoids peak and start egg deposition in May during OSR flowering (Williams 2006). They overwinter in their hosts in the ground and subsequently emerge from the soil of the last year's OSR crop area.

\section{Data collection}

Samples of rape pollen beetles were collected from the phytometers at flowering of wild mustard (27 June 2006) by clipping all flowering stalks and storing them in plastic cups at $-22^{\circ} \mathrm{C}$. The number of parasitized larvae was determined by dissecting the rape pollen beetle larvae under a binocular (Zeiss, Stemi SV 11). Parasitoid eggs were assigned to the parasitoid species by their typical pigmentation (black:T. heterocerus; white: Phradis spp.). Because we found only 1-2 individuals of Phradis spp. in two different landscapes, only $T$. heterocerus was included for further analyses. After peak ripening, we collected all remaining Sinapis plants and stored them at $1{ }^{\circ} \mathrm{C}$ (15 July 2006). Plant damage to seed set was quantified by counting the number of pods and the podless stalks that remained after rape pollen beetle herbivory.

Landscape parameters were estimated on the basis of the official digital thematic maps (ATKIS - Digitales Landschaftsmodell 25/1; Landesvermessung und Geobasisinformation, Hannover, Germany, 1991-1996) containing areal measures of arable land, grassland, forests, hedgerows, garden land and settlement. In addition, we mapped habitat types in the field during the season, allowing a specific classification of land use in the areas with arable land (Online Resource 4). Data were digitized and analyzed in ArcView 3.2 (ESRI, Redlands, CA, USA) in a radius of $750 \mathrm{~m}$ around each experimental patch, since this scale has been shown to be appropriate for the studied host-parasitoid interactions (Thies et al. 2003). Habitats were also characterized by vegetation surveys using the Braun-Blanquet scale (Braun-Blanquet 1964). The surveys were conducted within 2 weeks at the beginning of the study period on five randomly chosen plots per habitat of $2 \times 2 \mathrm{~m}$ each. Turboveg 2.79 (Hennekens and Schaminée 2001) was used to transform Braun-Blanquet data into plant percentage cover data and to analyze number and abundance of plant species (Online Resource 2).

\section{Data analyses and statistics}

Variation of adult rape pollen beetle numbers on the sampled phytometer may, in part, be due to diurnal activity patterns. Therefore, we included only the rape pollen beetle larvae in our analyses. Missing phytometer plants due to mammalian herbivory were treated as NA in the statistical analyses. Although being standardized, the phytometers had different numbers of flowering stalks by the time we collected the samples of rape pollen beetles. This variation, however, was not correlated to habitat type (Online Resource 3) or to any landscape parameters (Online Resource 1). To account for the varying sample size, we analyzed our data with the larval abundance divided by the number of flowers in the respective samples. Larvae per flower and parasitism rates in experimetal patches were arcsine square-root transformed and landscape and habitat type effects were tested in lme models (Pinheiro et al. 2009) in R 2.9.11 (R Development Core Team 2009). Obtaining normally distributed residuals after the transformation, we could use the more established and widely 
used lme models instead of generalized linear mixed models for analyzing non-normal data, which are more difficult to fit appropriately (Bolker et al. 2009).

Maximal models contained the following landscapescale predictors: (1) \% arable land, selected a priori based on our experimental design; (2) \% OSR, as important predictor due to the focus of spillover from OSR into other habitats; (3) a small set of additional landscape-scale predictors shown to be important based on inspection of zero-order correlation matrices (Murray and Conner 2009), namely the mean perimeter to area ratio (MPAR) and the number of arable land patches in the landscape (Online Resource 4). MPAR gives information about the complexity of a landscape (see Bianchi et al. 2006). Low values of MPAR indicate large patches in a landscape whilst landscapes with high MPAR values are characterized by many small patches of fields and habitats, thus the number of different resource types tends to increase with MPAR. Local effects comprised habitat type and the number of larvae per flower. The maximum models were fitted as

$y=\mathbf{X} \beta+\mathbf{Z} b+\varepsilon$

where $y$ is the response variable (larvae per flower, parasitism rate), $\mathbf{X}$ is a fixed-effects regressor matrix, $\beta$ is the vector of coefficients for local and landscape effects (fixed effects coefficients), $b$ is a vector of random effects for landscapes, $\mathbf{Z}$ is a random-effects regressor matrix, and $\varepsilon$ is a vector of independently and normally distributed errors (Pinheiro and Bates 2000). Two-way interactions were included. The random effect landscape (with eight levels) was included to represent nesting of habitats in landscapes. Landscape measures and habitat type were ordered according to the spatial scale, (i.e., large-scale effects prior to habitat type).

For each response variable, we used a stepwise AICc function, an information-theoretical approach for small sample sizes (Burnham and Anderson 2002), to find the minimal adequate model. Two maximum models were calculated for the response variable parasitism rate: first, we included conservatively only the design variables, (i.e., landscape effects and habitat type); the second, also included the number of larvae per flower which is a possible predictor for parasitism rates but was not initially included in the experimental design.

Seed number, seed weight, fruit set and destroyed buds were estimated per plant. These plant performance measurements were transformed, if necessary, before we fitted lme-models with landscape effects (see above), habitat type, larval infestation, podless stalks and parasitism as explanatory variables. To examine habitats for differences in species richness and evenness, we applied an ANOVA with Tukey's HSD post-hoc test (Hothorn et al. 2008).
Means were calculated as arithmetic means, unless stated otherwise.

\section{Results}

Rape pollen beetle larvae

The minimal adequate model (Online Resource 5) for the prediction of rape pollen beetle larvae per flower included MPAR and habitat type as explanatory variables. Rape pollen beetle larvae responded negatively to landscape complexity (MPAR) on the landscape scale $\left(F_{1,25}=16.36\right.$, $p<0.001$; Fig. 1). High larval numbers were observed in simple landscapes $(\mathrm{MPAR}=0.05)$, whilst observations were low in complex landscapes $(\mathrm{MPAR}=0.20$; Online Resource 1). Other landscape parameters (in particular the proportion of OSR) had no significant effect on larval density. Habitat type significantly affected larvae per flower $\left(F_{4,25}=3.13, p=0.032\right)$. Cereal fields $(0.34 \pm$ $0.05)$ and field margins $(0.27 \pm 0.05)$ had higher numbers of larvae per flower than fallow $(0.21 \pm 0.05)$, grassland $(0.16 \pm 0.03)$ and wood margin $(0.14 \pm 0.04$; Online Resource 3). Significant differences of larvae per flower occurred only between cereal fields and field margins on the one hand and fallow, grassland and wood margin on the other hand (Tukey test; Fig. 1).

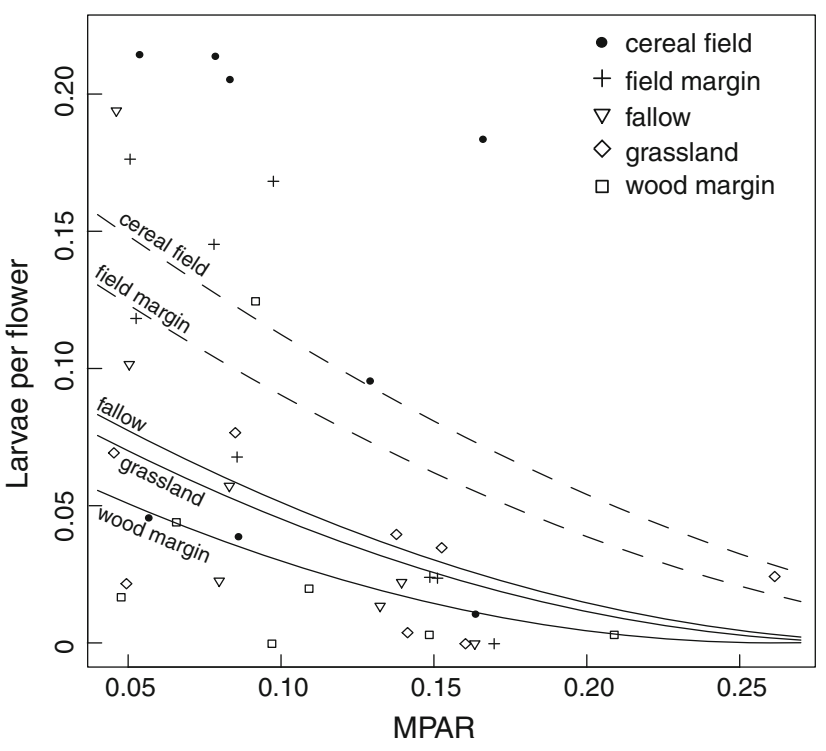

Fig. 1 The back-transformed data of larvae per flower as a function of the significant MPAR (MPAR: low values indicate simple, high values complex landscape structure) for each of the five tested habitats. The lines represent model predictions of larval infestation for each of the habitats. Wheat and field margin (dashed lines) had significantly higher larval infestation than grassland, fallow and wood margin (solid lines). Lines of the same type do not differ significantly from each other (Tukey's HSD) 


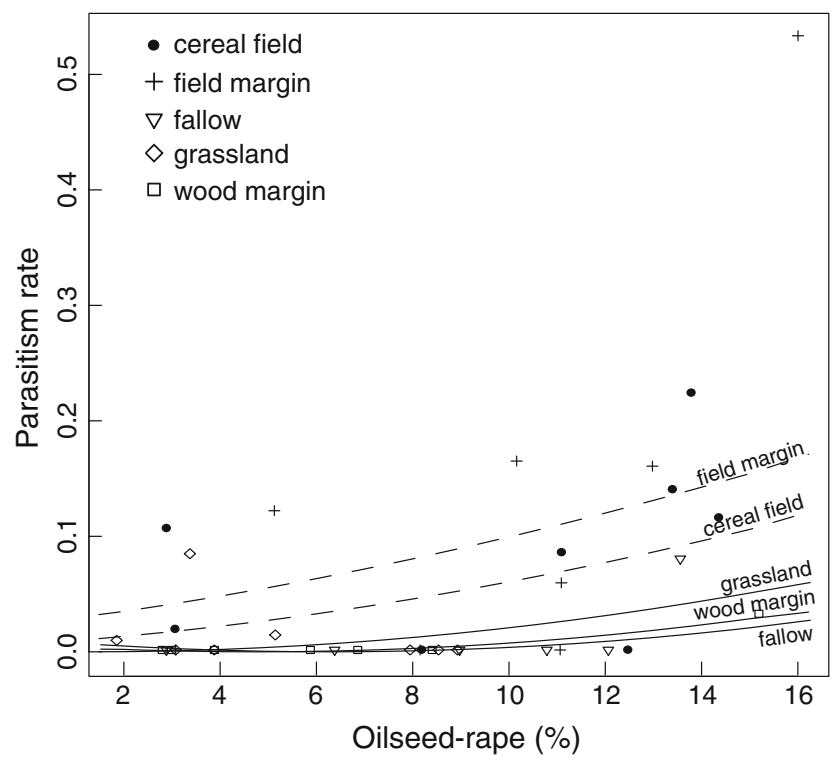

Fig. 2 Back-transformed data of parasitism rates as a function of percentage of oilseed rape crop area for each of the tested habitats. The lines represent model predictions of parasitism rates in each of the habitats. Parasitism rates were significantly higher in wheat fields and field margins (dashed lines) than in grassland, fallow and wood margins (solid lines). Lines of the same type do not differ significantly from each other. Also significant was the increase with OSR crop area

Parasitism rates

At the landscape scale, parasitism rates responded only to $\%$ OSR crop area $\left(F_{1,23}=13.06, p=0.002\right.$; Figs. 2 and 3 ;
Online Resource 5). Locally, host density, (i.e., larvae per flower; $\left.F_{1,23}=6.84, \quad p=0.015\right)$ and habitat type $\left(F_{4,21}=2.88, p=0.047\right)$ were significant predictors. Since these two factors correlated with each other, we calculated two different models, the design model with \% OSR and habitat type (Fig. 2), and the model that included \% OSR crop area and larvae per flower (Fig. 3). Parasitism rates increased more strongly with larval density if OSR crop area was high as shown by the interaction between both factors $\left(F_{1,23}=6.09, p=0.022\right.$; Fig. 3). In landscapes with a low OSR crop area of $2 \%$, parasitism was not observed, or only at rates below $10 \%$. Parasitism rates by $T$. heterocerus increased with larvae per flower and increasing proportion of OSR crops (up to a maximum of $50 \%$, Fig. 3 ).

\section{Plant performance}

The seed set of $S$. arvensis plants was not significantly influenced by any of the landscape variables nor by habitat type, the minimal adequate model was the null-model (Online Resource 5). A lme-model including the number of branches as a measure for plant size and podless stalks as a measure for herbivory (and landscape as random effect) explained the weight of all seeds of a plant, (i.e., yield) best. Total seed weight increased significantly with the number of branches $\left(F_{1,19}=8.88, \quad p=0.008\right)$ and decreased with the number of podless stalks $\left(F_{1,19}=4.77\right.$, $p=0.042$ ). Surprisingly, the amount of rape pollen beetle

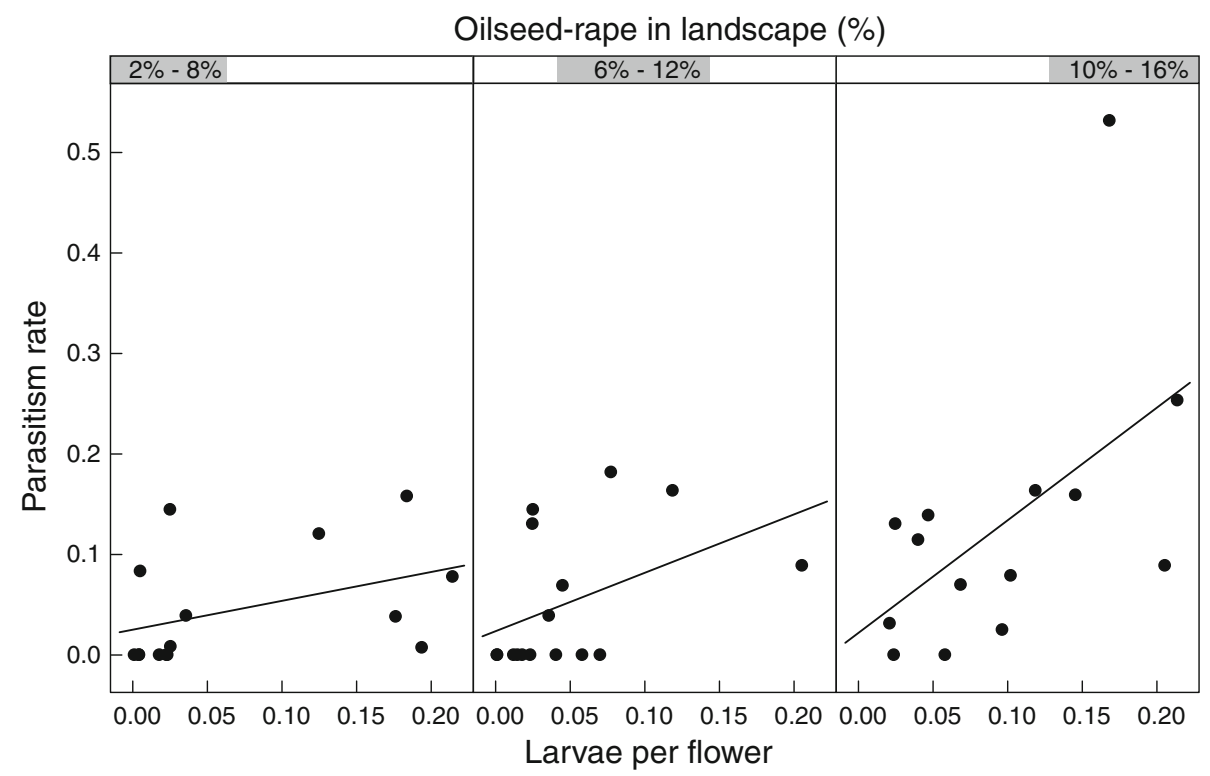

Fig. 3 Back-transformed parasitism rates as a function of the interaction between larval infestation and three categories of oilseed rape crop area (indicated by the shaded areas and the percentage values at the top). Note that this figure was created using the percentage of OSR as a conditioning variable (see Becker and
Cleveland 1996; Sarkar 2008). Graphs are overlapping for OSR crop area to avoid too distinct separations of this continuous variable. Parasitism rates responded positively to larval densities and OSR crop area. The synergistic interaction between larvae per flower and rape crop area is apparent in the increasing slope from left to right 
larvae per flower however could not be linked to the number of podless stalks $(p=0.633)$.

\section{Discussion}

We showed that both landscape and local factors affect the abundance of rape pollen beetles (M. aeneus) and parasitism by $T$. heterocerus. Whilst the reaction to habitat type was similar, both species responded to different landscape parameters. We found the hypothesized spillover from OSR crop onto wild plants in surrounding habitats only for parasitism, but not for pollen beetles, providing one of the first pieces of evidence for shifts in trophic interactions caused by organisms emigrating from cropland.

Habitat type effects on rape pollen beetle larvae

Twice as many rape pollen beetle larvae per flower were found on phytometer plants in cropland habitats such as wheat fields and adjacent field margins in comparison to numbers in the semi-natural habitats (grassland, fallow, wood margin). The higher colonization of phytometers in cropland habitats may be the result of a multiannual population build-up of this crop inhabiting species (Rand and Tscharntke 2007). Crop rotation with periodic availability of mass-flowering resources has been shown to change landscape-wide densities of associated organisms (Thies et al. 2008). The higher colonization of phytometers support this study and reflect elevated densities of rape pollen beetles in cropland habitats. In contrast, near-natural habitats provide resources constantly, but at a lower level, thus preventing the establishment of high pollen beetle abundances.

\section{Habitat type effects on parasitism}

Similar to the results of the larval density of rape pollen beetles, parasitism rates were high in wheat fields and field margins and low in the other three habitat types, i.e., parasitoids were more successfull than their hosts in crop systems.

Parasitism rates increased with larval density (as, for example, in Elzinga et al. 2007), indicating that higher numbers of larvae can be detected more easily. Since T. heterocerus is highly specific to the olfactory signals of (infected) Brassicaceae (Lewis and Tumlinson 1988; Vet et al. 1995; Renwick 2002; Wackers 2004; Jönsson et al. 2005; Jönsson and Anderson 2007), parasitoids concentrated on host plants with high rape pollen beetle infestation. Thus, habitat triggered infestation levels of S. arvensis with rape pollen beetle larvae and thereby even stronger parasitism rates.
Landscape-scale effects on rape pollen beetle larvae

The numbers of rape pollen beetle larvae on the phytometer plants decreased with an increase of landscape complexity, which is in line with some previous studies (Thies and Tscharntke 1999; Thies et al. 2003; but see Zaller et al. 2008b). Simple landscapes may support a population buildup of rape pollen beetles over many years, because they consist of large arable crop patches (including OSR) with uniform resources (Grilli and Bruno 2007). Complex landscapes, in contrast, have scattered small patches of different resource types and thus are likely not to provide enough supply for local mass-populations.

In contrast to our expectation that OSR fields are the main source for spillover of rape pollen beetles, we found no correlation between OSR area and infestation rates of the rape pollen beetle larvae. This is in line with Thies et al. (2008), but in contrast to other studies suggesting pest pressure to increase with cropping area (Jonsen and Fahrig 1997; den Belder et al. 2002; Klug et al. 2003). The lack of response to OSR crop area may be a result of large-scale dispersal patterns (Thies et al. 2008), intraspecific larval competition on the phytometers (Nilsson 1988; Ekbom 1998; Hokkanen 2000), or due to abscission of heavily infected buds (Williams 2004).

\section{Landscape-scale effects on parasitism}

Oilseed rape appeared to be a great source of parasitoids in June. The positive correlation between parasitism rates and OSR crop area indicates that the parasitoids shift from OSR to other (more limited) resources in the landscape after depletion of hosts in OSR fields. This supports similar results of Thies et al. (2008), who showed that reductions of OSR between years enhanced parasitism. Apart from the positive effect on parasitism rates, OSR crop area interacted significantly with the number of rape pollen beetle larvae. The increase of OSR crop area intensified the positive response of parasitism rates on host density, i.e., larvae per flower. This is possibly the consequence of an easier detection at higher host densities combined with a higher availability of parasitoids from larger OSR areas. Despite these spillover and concentration effects on the landscape scale, mean parasitism rates remained at a low level ( $<20 \%$; Figs. 2 and 3 ). Two mechanisms may explain this pattern. First, parasitoid populations peak in May (Williams 2006). With a limited lifespan of 1-2 weeks during the summer (Nilsson 2003), the observed parasitism rates may be the result of a declining population. Second, Elzinga et al. (2007) reported that parasitoids occur with lower frequency in small patches compared to larger ones. The three phytometer plants established in the habitats constitute a small patch in contrast to the OSR and this is 
why the observed parasitism rates ranged below the ones that are usually observed in OSR crops (T. heterocerus parasitism rate 0.2-0.3; Thies et al. 2003).

Thies et al. (2008) considered the regional population pool, (i.e., the pool present within OSR areas) more important for biological control than local management (in their case establishing field margins), and stated that parasitoids in agricultural landscapes can be strongly influenced by interannually changing crops. Thus, the lack of response of parasitism to the area of semi-natural habitats in a landscape can be best explained with the specialization of $T$. heterocerus which binds the parasitoid strongly to the area of OSR. Further, the response of parasitoids, but not herbivores, to changes in OSR area with corresponding changes in parasitism rates supports the general idea that parasitoids are more sensitive to disturbances and environmental change than their hosts (Kruess and Tscharntke 1994; Holt et al. 1999; Elzinga et al. 2007).

\section{Seed set of Sinapis arvensis}

The decrease of total seed weight per phytometer plant with an increase of podless stalks indicated that herbivory negatively affected the yield of $S$. arvensis. Podless stalks are a typical sign of herbivory by rape pollen beetles (Thies and Tscharntke 1999). However, the number of rape pollen beetles or their larvae was not related to the number of podless stalks. This may have been caused by the fact that the observed herbivory is not only due to the rape pollen beetle numbers at the time of collection but also a result of continuous herbivory throughout the experiment. Second, loss of ripe pods due to maturity of the phytometer plants (Bruce et al. 2002) may account for variation that remains unexplained.

\section{Conclusions}

Landscape-scale factors explained the observed change of insect trophic interactions more than habitat type due to spillover. Mortality of rape pollen beetles by parasitism was higher in simple landscapes with a high proportion of OSR crops. The response of parasitism to host density profited particularly well from a larger proportion of OSR in the landscape. Positive density dependence in parasitoids is widespread and a basis of successful biological control stabilizing prey populations at low levels (Hassell and May 1974). According to our results, parasitoid spillover from cropland may significantly influence trophic interactions in wild habitats, which is rarely shown, but should be widespread shaping natural food webs.
Acknowledgments We thank K. Eckel, K. Krewenka, G. Hornemann, F. Goedecke and P. Weigelt for their help in the field and the farmers for providing their field-sites. We would also like to thank Jay A. Rosenheim and two anonymous referees for comments on an earlier version of this manuscript. Funding by the BESS (Biotic Ecosystem Services) project of the Helmholtz Association of German Research Centres (VH-NG-247) is acknowledged.

Open Access This article is distributed under the terms of the Creative Commons Attribution Noncommercial License which permits any noncommercial use, distribution, and reproduction in any medium, provided the original author(s) and source are credited.

\section{References}

Alford DV, Nilsson C, Ulber B (2005) Insect pests of oilseed rape crops. In: Alford DV (ed) Biocontrol of oilseed rape pests. Blackwell, Oxford, pp 9-42

Becker RA, Cleveland WS (1996) The design and control of trellis display. J Comput Stat Graph 5:123-155

Bianchi F, Booij CJH, Tscharntke T (2006) Sustainable pest regulation in agricultural landscapes: a review on landscape composition, biodiversity and natural pest control. Proc R Soc Lond B 273:1715

Billqvist A, Ekbom B (2001) The influence of host plant species on parasitism of pollen beetles (Meligethes spp.) by Phradis morionellus. Entomol Exp Appl 98:41-47

Bolker BM, Brooks ME, Clark CJ, Geange SW, Poulsen JR, Stevens MHH, White JS (2009) Generalized linear mixed models: a practical guide for ecology and evolution. Trends Ecol Evol 24:127-135

Braun-Blanquet J (1964) Pflanzensoziologie. Grundzüge derVegetationskunde. Springer, Wien

Bromand B (1983) Possibility of continuous rearing of Meligethes aeneus Fabr. (Col.). J Appl Entomol 96:419-422

Bruce DM, Farrent JW, Morgan CL, Child RD (2002) PA-precision agriculture: determining the oilseed rape pod strength needed to reduce seed loss due to pod shatter. Biosyst Eng 81:179-184

Büchi R (2002) Mortality of pollen beetle (Meligethes spp.) larvae due to predators and parasitoids in rape fields and the effect of conservation strips. Agric Ecosyst Environ 90:255-263

Burnham KP, Anderson (2002) Information and likelihood theory: a basis for model selection and inference. In: Burnham KP(ed) Model selection and multimodel inference, Springer, New York, pp 49-97

Charpentier R (1985) Host plant selection by the pollen beetle Meligethes aeneus. Entomol Exp Appl 38:277-285

Cook SM, Smart LE, Martin JL, Murray DA, Watts NP, Williams IH (2006) Exploitation of host plant preferences in pest management strategies for oilseed rape (Brassica napus). Entomol Exp Appl 119:221-229

Cushman SA, McGarigal K (2004) Patterns in the species-environment relationship depend on both scale and choice of response variables. Oikos 105:117-124

Dauber J, Purtauf T, Allspach A, Frisch J, Voigtländer K, Wolters V (2005) Local vs. landscape controls on diversity: a test using surface-dwelling soil macroinvertebrates of differing mobility. Global Ecol Biogeogr 14:213-221

den Belder E, Elderson J, van den Brink W, Schelling G (2002) Effect of woodlots on thrips density in leek fields: a landscape analysis. Agric Ecosyst Environ 91:139-145

Ekbom B (1998) Clutch size and larval performance of pollen beetles on different host plants. Oikos 83:56-64 
Ekbom B, Borg A (1996) Pollen beetle (Meligethes aeneus) oviposition and feeding preference on different host plant species. Entomol Exp Appl 78:291-299

Elzinga J, van Nouhuys S, van Leeuwen D, Biere A (2007) Distribution and colonisation ability of three parasitoids and their herbivorous host in a fragmented landscape. Basic Appl Ecol 8:75-88

Gardiner MM, Landis DA, Gratton C, DiFonzo CD, O'Neal M, Chacon JM, Wayo MT, Schmidt NP, Mueller EE, Heimpel GE (2009) Landscape diversity enhances biological control of an introduced crop pest in the north-central USA. Ecol Appl 19:143-154

Grilli MP, Bruno M (2007) Regional abundance of a planthopper pest: the effect of host patch area and configuration. Entomol Exp Appl 122:133-143

Gurr GM, Wratten SD, Luna JM (2003) Multi-function agricultural biodiversity: pest management and other benefits. Basic Appl Ecol 4:107-116

Hassell MP, May RM (1974) Aggregation of predators and insect parasites and its effect on stability. J Anim Ecol 13:567-594

Haynes KJ, Dillemuth FP, Anderson BJ, Hakes AS, Jackson HB, Elizabeth Jackson S, Cronin JT (2007) Landscape context outweighs local habitat quality in its effects on herbivore dispersal and distribution. Oecologia 151:431-441

Hennekens SM, Schaminée JH (2001) TURBOVEG, a comprehensive data base management system for vegetation data. J Veg Sci 12:589-591

Hokkanen HMT (2000) The making of a pest: recruitment of Meligethes aeneus onto oilseed Brassicas. Entomol Exp Appl 95:141-149

Holt RD, Lawton JH, Polis GA, Martinez ND (1999) Trophic rank and the species-area relationship. Ecology 80:1495-1504

Hooper DU, Chapin FS, Ewel JJ, Hector A, Inchausti P, Lavorel S, Lawton JH, Lodge DM, Loreau M, Naeem S, Schmid B, Setälä H, Symstad AJ, Vandermeer J, Wardle DA (2005) Effects of biodiversity on ecosystem functioning: a consensus of current knowledge. Ecol Monogr 75:3-35

Hopkins R, Ekbom B (1996) Low oviposition stimuli reduce egg production in the pollen beetle Meligethes aeneus. Physiol Entomol 21:118-122

Hothorn T, Bretz F, Westfall P (2008) Simultaneous inference in general parametric models. Biom J 50:346-363

Jonsen I, Fahrig L (1997) Response of generalist and specialist insect herbivores to landscape spatial structure. Landsc Ecol 12:185-197

Jönsson M, Anderson P (2007) Emission of oilseed rape volatiles after pollen beetle infestation; behavioural and electrophysiological responses in the parasitoid Phradis morionellus. Chemoecology 17:201-207

Jönsson M, Lindkvist A, Anderson P (2005) Behavioural responses in three ichneumonid pollen beetle parasitoids to volatiles emitted from different phenological stages of oilseed rape. Entomol Exp Appl 115:363-369

Jourdheuil P (1960) Influence de quelques facteurs écologiques sur les fluctuations de population d'une biocénose parasitaire. Etude à quelques Hymenoptère parasites de divers Coéoptères inféodés aux Crucifères. Ann Epiphyties 11:445-660

Kareiva P, Wennergren U (1995) Connecting landscape patterns to ecosystem and population processes. Nature 373:299-302

Klug T, Gathmann A, Poehling H, Meyhöfer R (2003) Areadependent effects of landscape structure on the colonisation of spinach cultures by the silver Y moth Autographa gamma L., Lepidoptera: Noctuidae) in Western Germany. In: IOBC/wprs Bulletin. Proceedings of the 1st Meeting at Bologna (Italy), pp 77-83
Kruess A, Tscharntke T (1994) Habitat fragmentation, species loss, and biological control. Science 264:1581-1584

Lehrman A, Åhman I, Ekbom B (2008) Effect of pea lectin expressed transgenically in oilseed rape on pollen beetle life-history parameters. Entomol Exp Appl 127:184-190

Lewis W, Tumlinson J (1988) Host detection by chemically mediated associative learning in a parasitic wasp. Nature 331:257-259

Matter S, Roland J (2002) An experimental examination of the effects of habitat quality on the dispersal and local abundance of the butterfly Parnassius smintheus. Ecol Entomol 27:308-316

Meyer B, Jauker F, Steffan-Dewenter I (2009) Contrasting resourcedependent responses of hoverfly richness and density to landscape structure. Basic Appl Ecol 10:178-186

Müller H (1941) Weitere Beiträge zur Biologie des Rapsglanzkäfers Meligethes aeneus F. (Ueber das Winterlager und die Massenbewegung im Frühjahr). Z Pflkrankh PflPath PflSchutz 51:529-595

Murray K, Conner MM (2009) Methods to quantify variable importance: implications for the analysis of noisy ecological data. Ecology 90:348-355

Nilsson C (1988) The pollen beetle (Meligethes aeneus F.) in winter and spring rape at Alnarp 1976-1978. III. Mortality factors. Växtskyddsnotiser 52:145-150

Nilsson C (2003) Parasitoids of pollen beetless. In: Alford DV (ed) Biocontrol of oilseed rape pests. Blackwell, Oxford, pp 73-86

Pinheiro JC, Bates DM (2000) Theory and computational methods for linear mixed-effects models. In: Sheather S, Tierney L (eds) Mixed-effects models in S and S-PLUS. Springer, New York, pp 57-96

Pinheiro J, Bates D, DebRoy S, Sarkar D, the R Core team (2009) nlme: Linear and nonlinear mixed effects models. R package version 3:1-92

R Development Core Team (2009) R: A language and environment for statistical computing. R Foundation for Statistical Computing, Vienna, Austria

Rand TA, Louda SM (2006) Spillover of agriculturally subsidized predators as a potential threat to native insect herbivores in fragmented landscapes. Conserv Biol 20:1720-1729

Rand TA, Tscharntke T (2007) Contrasting effects of natural habitat loss on generalist and specialist aphid natural enemies. Oikos 116:1353

Rand TA, Tylianakis JM, Tscharntke T (2006) Spillover edge effects: the dispersal of agriculturally subsidized insect natural enemies into adjacent natural habitats. Ecol Lett 9:603-614

Renwick J (2002) The chemical world of crucivores: lures, treats and traps. Entomol Exp Appl 104:35-42

Ricketts TH, Regetz J, Steffan-Dewenter I, Cunningham SA, Kremen C, Bogdanski A, Gemmill-Herren B, Greenleaf SS, Klein AM, Mayfield MM (2008) Landscape effects on crop pollination services: are there general patterns? Ecol Lett 11:499-515

Sarkar D (2008) Lattice: multivariate data visualization with R. Springer, New York

Schweiger O, Maelfait JP, Wingerden W, Hendrickx F, Billeter R, Speelmans M, Augenstein I, Aukema B, Aviron S, Bailey D (2005) Quantifying the impact of environmental factors on arthropod communities in agricultural landscapes across organizational levels and spatial scales. J Appl Ecol 42:1129-1139

Thies C, Tscharntke T (1999) Landscape structure and biological control in agroecosystems. Science 285:893

Thies C, Steffan-Dewenter I, Tscharntke T (2003) Effects of landscape context on herbivory and parasitism at different spatial scales. Oikos 101:18-25

Thies C, Steffan-Dewenter I, Tscharntke T (2008) Interannual landscape changes influence plant-herbivore-parasitoid interactions. Agric Ecosyst Environ 125:266-268 
Tscharntke T, Rand TA, Bianchi F (2005) The landscape context of trophic interactions: insect spillover across the crop-noncrop interface. Ann Zool Fenn 42:421-432

Turner MG (1989) Landscape ecology: the effect of pattern on process. Annu Rev Ecol Syst 20:171-197

Turner MG, Gardner RH (1991) Quantitative methods in landscape ecology: an introduction. In: Turner MG, Gardner RH (eds) Quantitative methods in landscape ecology. Springer, New York, pp 3-14

Vet LEM, Lewis WJ, Cardé RT (1995) Parasitoids foraging and learning. In: Cardé RT, Bell WJ (eds) Chemical of ecology insects 2. Chapman and Hall, London, pp 65-104

Wackers F (2004) Assessing the suitability of flowering herbs as parasitoid food sources: flower attractiveness and nectar accessibility. Biol Control 29:307-314

Williams IH (2004) Advances in insect pest management of oilseed rape in Europe. In: Horowitz AR, Ishaaya I (eds) Insect pest management-field and protected crops. Springer, Heidelberg, pp 181-208

Williams IH (2006) Integrating parasitoids into management of pollen beetle on oilseed rape. Agron Res 4:465-470

Wrbka T, Erb K, Schulz NB, Peterseil J, Hahn C, Haberl H (2004) Linking pattern and process in cultural landscapes. An empirical study based on spatially explicit indicators. Land Use Policy 21:289-306

Zaller JG, Moser D, Drapela T, Schmöger C, Frank T (2008a) Effect of within-field and landscape factors on insect damage in winter oilseed rape. Agric Ecosyst Environ 123:233-238

Zaller JG, Moser D, Drapela T, Schmöger C, Frank T (2008b) Insect pests in winter oilseed rape affected by field and landscape characteristics. Basic Appl Ecol 9:682-690

Zhang W, Ricketts T, Kremen C, Carney K, Swinton S (2007) Ecosystem services and dis-services to agriculture. Ecol Econ 64:253-260 